\title{
Recent management of esophago-gastric adenocarcinoma
}

\author{
Chevallay Mickael $^{1}$, Jung Minoa ${ }^{1}$, Niclauss Nadja $^{1}$, Morel Philippe $^{1}$ and Mönig Stefan ${ }^{1 *}$ \\ ${ }^{1}$ Visceral surgery Department, Geneva University Hospital, Rue Gabrielle-Perret-Gentil 4, 1205 Genève, Switzerland
}

\begin{abstract}
At the border between the esophagus and the stomach, gastro-esophageal junction tumors require a specific management that cannot be simplified to either of these two organs. Staging work-up with endoscopy, endosonography and PET-Scan is essential because it will condition the choice of neoadjuvant treatment and of surgical approach. Surgery remains the only curative treatment and should be undergone in specialized center.
\end{abstract}

\section{Introduction}

Esophagogastric junction adenocarcinomas are tumors, which develop near the anatomic junction between the esophagus and the stomach. It is rather a zone disease than that of an organ. Management is specific, using principles of management of esophagus and stomach cancer. Their incidence is constantly increasing since the last 20 years with an increase of 4 to $10 \%$ per year in Europe. In Western world, early stages are rare and the majority of patients are diagnosed in an advanced stage with poor prognosis. In comparison, survival rate are better in Asian countries where national screening programs allow for earlier diagnosis. Risk factors for development of esophagogastric junction tumors are male, obesity, tobacco use and metaplasia of the esophageal epithelium (Barrett esophagus).

\section{Classification}

The limit between esophagus and the stomach can be defined in two ways: anatomically with the hiatus diaphragmatic passage or histologically with the transition between the esophagus squamous epithelium to the gastric prismatic cells. Anatomical localization is used during endoscopic evaluation as the histological transition can be altered in case of metaplasia. Ending of the longitudinal symmetrical mucosal folds of the gastric fundus set the transition between the esophagus and the stomach. The classification relying on the anatomical topography proposed by Siewert et al. [1] divide the esophagogastric junction tumors in 3 types according to the localization of the tumor center according to the esophagogastric junction:

Type I: distal esophagus adenocarcinoma. Tumor center is 1 to 5 $\mathrm{cm}$ above the esophagogastric junction.

Type II: true cardia tumor. Tumor center is $1 \mathrm{~cm}$ above to $2 \mathrm{~cm}$ under the junction.

Type III: cardial region tumor. Tumor center is 2 to $5 \mathrm{~cm}$ under the junction.

The three types do not behave the same in term of prognostic and lymphatic invasion. Hiatal hernia or deformation by the tumor itself can limit the application of this classification.

Since 2016, TNM classification (10th edition) defines the junction cancer as all tumors which center is found 2 centimeters proximal or distal to the junction (Figure 1). This classification is the application of the Nishi gradation used by the Japanese.

\section{Diagnostic}

The main symptoms in patients with esophagogastric junction tumor are dysphagia and weightloss. Eso-gastroduodenoscopy (OGD) is the first exam in the complementary workup. It allows the classification of the tumor according to Siewert and to collect biopsies. Echo-endoscopy evaluates local invasion and regional lymph node. However in this last case, diagnostic accuracy is limited by the fact that tumor invasion is not well correlated with the size of the lymphadenopathy [2]. Endoscopy can be therapeutic in early tumors (Tis, T1a) by doing endoscopic resection. To evaluate distant lesion, thoraco-abdominal Ct-Scan allow to clarify the number of regional lymph node and eventual metastasis with the most frequent sites being the liver, lungs and retro-peritoneal lymphadenopathy. This modality is not used to localize the tumor as the endoscopy is more accurate and the scanner overestimates the tumor size. The PET-Scan finds in 15 to $20 \%$ of cases metastasis non visible on the Ct-Scan [3]. Some histologic subtypes, in particular non cohesive tumor (signet ring cell), pick up less contrast and the staging by PET-Scan will be less precise in these cases [4]. Imaging cannot evaluate reliable presence of peritoneal metastasis and some experts propose explorative laparoscopy as complement workup. Nutritional consultation is part of the evaluation of these patients often malnourished, in bad condition before the start of neoadjuvant treatment or surgery. If classical feeding is not possible, enteral nutrition is the best option with jejunostomy in first intention, better than naso-jejunal tube or percutaneous endoscopic gastrostomy, which is of risk for a potential gastric pull up.

Esophagogastric junction tumor with supraclavicular lymph nodes, distant metastasis or adjacent organs involvement (heart, great vessels, trachea) should not be resected out of clinical trials. A selection of patients with limited metastatic disease would benefit

Correspondence to: Mönig Stefan, Visceral surgery Department, Geneva University Hospital, Rue Gabrielle-Perret-Gentil 4, 1205 Genève, Switzerland, E-mail: Stefan.Moenig@hcuge.ch

Key words: oesophago-gastric junction, adenocarcinoma, surgery, laparoscopy

Received: May 10, 2017; Accepted: June 12, 2017; Published: June 14, 2017 


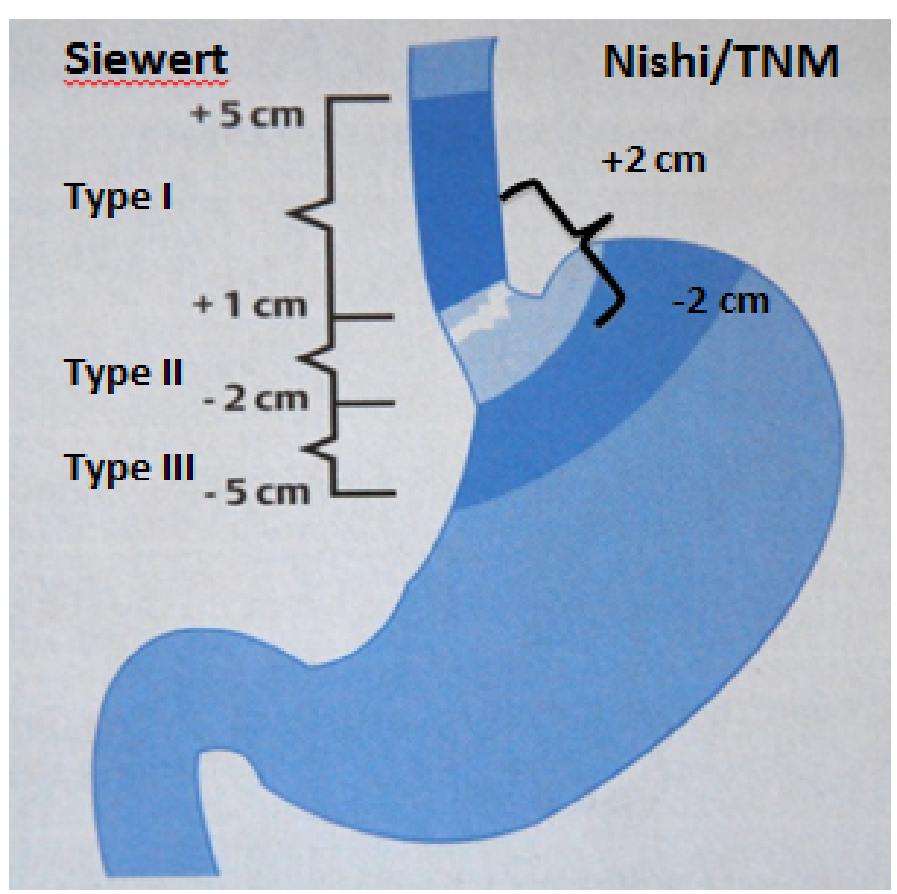

Figure 1. Siewert and Nishi classification for esophagogastric junction tumor.

from a multimodal approach [5]. Precise staging determines the best therapeutic strategy and improves the chance of complete resection and survival.

\section{Management}

\section{Neoadjuvant treatment}

Although surgery is the main important treatment, survival after resection is weak and multimodal approach should be the standard for locally advanced tumors. Goal of neo-adjuvant treatment is to shrink the tumor to achieve a higher rate of complete resection and to eradicate circulating tumor cells. All tumors that staging shows serosa involvement $(\mathrm{T} 3)$ or regional lymphadenopathy $(\mathrm{N}+)$ should receive neoadjuvant treatment. For tumors involving the muscularis propria (T2), indication should be discussed with the patient [6]. The majority of scientific evidence concerning junction tumor are an extrapolation of studies designed for esophagus or stomach tumors.

Notion of peri-operative chemotherapy has been introduce by two randomized trials:

The first one is an English trial (MAGIC-Trial) [7] from 2006 comparing overall survival between 253 patients with surgery alone and 250 patients with 6 chemotherapy perioperative cycles and surgery. This study showed a $13 \%$ better survival at 5 years.

The second is a French study (ACCORD-Trial) [8] from 2011 which compare also a group of 111 patients with surgery alone and 113 with surgery and 6 cycles of chemotherapy perioperative. This study showed also an improvement of survival of $14 \%$.

These two studies concluded an improvement of survival when chemotherapy was added in perioperative fashion. Since then, others combinations of chemotherapy regimen have been studied with one including Docetaxel with encouraging results $[9,10]$. To improve locoregional control and improve the rate of complete resection, the adding of radiotherapy has also been studied.
The reference study for radio-chemotherapy is a Dutch study (CROSS-Trial) [11] from 2012 comparing surgery alone (188 patients) to surgery with radio chemotherapy (178 patients). Resection rate with negative margin was greater in the group with neo-adjuvant treatment. Global survival was better in the neo adjuvant group (49.4 months $v s$. 24 months).

Each neoadjuvant treatment has its advantages and disadvantages: radiochemotherapy allow better loco-regional control but lesser than chemotherapy on eventually systemic metastasis. Table 1 resumes the different studies.

The actual recommendation is basing on the Siewert classification. Siewert I or II tumors with a need of neoadjuvant treatment should receive neoadjuvant radiochemotherapy and Siewert III perioperative chemotherapy [6].

However, the comparison between radiochemotherapy and chemotherapy alone would not show any differences in term of oncological results and survival. The choice between the two treatments is still under discussion [12].

\section{Surgical technique}

During surgery for oncologic indication, the main goal is to choose the best approach, which allow removing en bloc the primary tumor and the lymph nodes involved. Resection in negative margin is the priority (R0 resection) and should dictate the choice of surgical approach. Survival is influenced by this parameter: in a retrospective study of 1602 patients, 5 year survival was $43.2 \%$ for negative margin versus $11 \%$ for positive margin [13].

The localization between the thorax and the abdomen of junction tumors implies a potential dissemination in these two compartments.

Two surgical approaches for esophagogastric junction tumor are possible, especially in Siewert II tumors:

Thoraco-abdominal oesophagectomy: It is the oesophagectomy technique from Ivor-Lewis, which consist in a double surgical approach abdominal and thoracic. The intervention begins with a laparotomy or laparoscopy and confection of a gastric tube with the vascularization by the right gastroepiploic artery and abdominal lymphadenectomy. The small curvature of the stomach and the fundus are stapled and dissociated from the gastric tube. Intervention continues with right thoractomy or thoracoscopy during which esophagus is resected and medistinal lymph node harvested. High esogastric anastomosis (above the azygos vein) is made. Advantage of this approach is thoracic and abdominal lymphadenectomy and a safer negative resection margin. This procedure is recommended for Siewert I tumors [14]. Resection margin should be 5 centimeters above and distal from the tumor [15].

Total gastrectomy with distal esophagectomy: In this procedure, only abdominal approach is needed. It consists in total gastrectomy with lymph node harvested type D2+ that correspond to perigastric nodes, coeliac trunk, splenic artery, hepatic artery and lower mediastinal nodes. Distal esophagus is resected trans-hiatal (Figure 2). Roux-en-Y reconstruction is generally made with eso-jejunal anastomosis. This procedure doesn't imply thoracotomy making the thoracic lymphadenectomy limited. It is the surgical approach for Siewert III junction tumor.

In the cases of Siewert II tumors, no oncological benefit between oesophagectomy or gastrectomy has been demonstrated [16]. However, the development of minimally invasive techniques for esophagectomy permits to diminish the morbidity. Most of centers propose laparoscopic abdominal approach with gastric mobilization 
Table 1. Summary articles for multimodal treatment for esophagogastric tumors.

\begin{tabular}{|c|c|c|c|c|}
\hline Studies & Tumor of JOG proportion & Intervention & Survival & R0 resection \\
\hline MAGIC [8] & $26 \%$ & $\begin{array}{l}\text { Chemotherapy } \\
\text { perioperative }\end{array}$ & $\begin{array}{l}\text { Survival } 5 \text { years } \\
36 \% \text { surgery+chemotherapy } \\
23 \% \text { surgery alone }\end{array}$ & Non available \\
\hline ACCORD [9] & $75 \%$ & $\begin{array}{l}\text { Chemotherapy } \\
\text { perioperative }\end{array}$ & $\begin{array}{l}\text { Survival } 5 \text { years } \\
38 \% \text { surgery+chemotherapy } \\
24 \% \text { surgery alone }\end{array}$ & $\begin{array}{l}87 \% \text { surgery+chemotherapy } \\
74 \% \text { surgery alone }\end{array}$ \\
\hline CROSS [10] & $75 \%$ & $\begin{array}{l}\text { Radio-chemotherapy (RCT) } \\
\text { neoadjuvant }\end{array}$ & $\begin{array}{l}\text { Median survival } \\
49.4 \text { month } R C T+\text { surgery } \\
24 \text { month surgery alone }\end{array}$ & $\begin{array}{l}92 \% \mathrm{RCT}+\text { surgery } \\
69 \% \text { surgery alone }\end{array}$ \\
\hline
\end{tabular}

Table 2. Tumor characteristic and treatment options according to the Siewert classification.

\begin{tabular}{|l|l|l|l|}
\hline $\begin{array}{l}\text { Siewert } \\
\text { classification }\end{array}$ & Definition & $\begin{array}{l}\text { Multimodal } \\
\text { treatment }\end{array}$ & Surgery \\
\hline Type I & $\begin{array}{l}1 \text { to } 5 \mathrm{~cm} \text { above } \\
\text { the junction }\end{array}$ & $\begin{array}{l}\text { Radio- } \\
\text { chemotherapy or } \\
\text { chemotherapy }\end{array}$ & $\begin{array}{l}\text { Thoraco-abdominal } \\
\text { esophagectomy (Ivor Lewis) }\end{array}$ \\
\hline Type II & $\begin{array}{l}1 \mathrm{~cm} \text { above to } \\
2 \mathrm{~cm} \text { under the } \\
\text { junction }\end{array}$ & $\begin{array}{l}\text { Radio- } \\
\text { chemotherapy or } \\
\text { chemotherapy }\end{array}$ & $\begin{array}{l}\text { Thoraco-abdominal } \\
\text { esophagectomy or } \\
\text { gastrectomy (negative margin } \\
\text { resection is mandatory) }\end{array}$ \\
\hline Type III & $\begin{array}{l}2 \text { to } 5 \mathrm{~cm} \text { under } \\
\text { the junction }\end{array}$ & Chemotherapy & $\begin{array}{l}\text { Total gastrectomy with distal } \\
\text { esophagectomy }\end{array}$ \\
\hline
\end{tabular}

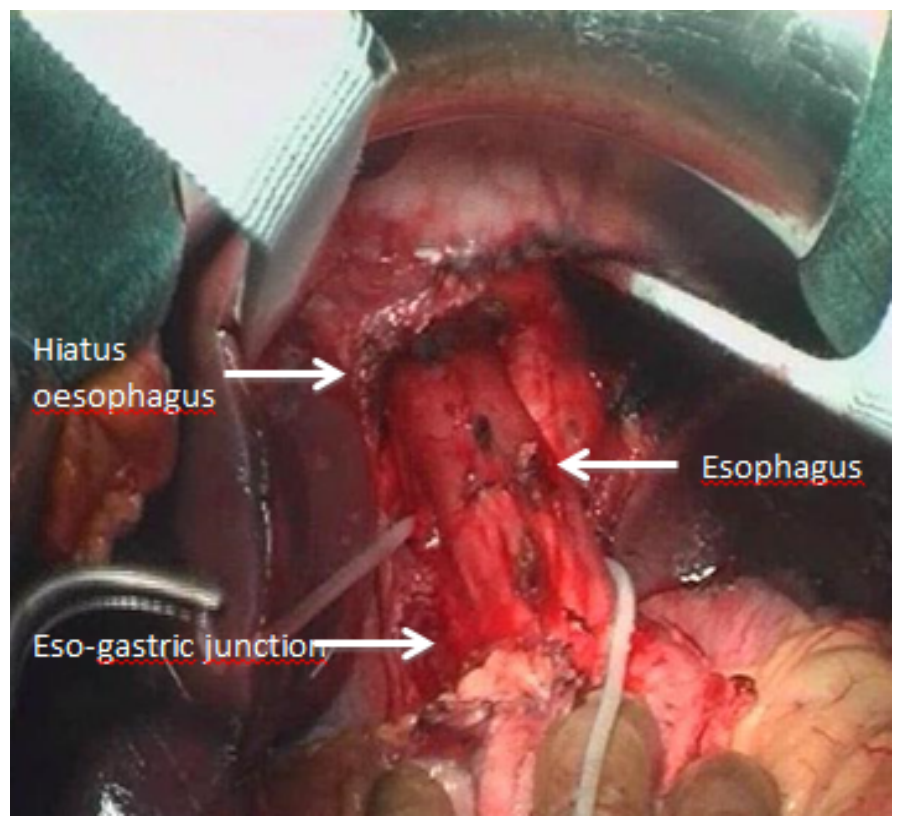

Figure 2. Total gastrectomy with distal esophagectomy for Siewert III tumor.

and pull up of the stomach through the diaphragmatic hiatus. Thoracic time is then performed open (Hybrid technique) [17].

The comparison of laparoscopic approach and open for the abdominal time is the subject of a French Study (MIRO-Trial), which shows a clear benefit for this hybrid minimally invasive approach [18]. Table 2 resumes the treatment for junction tumor according to the Siewert Classification.

\section{Conclusion}

Esophagogastric junction tumors represent a subtype of cancer that incidence increases in the Western world. The classification according to the localization of the tumor (Siewert classification) and the extension staging are the basis for therapeutic decision. Surgery is still the only curative treatment and should be done in specialized centers.
Prevalence of locally advanced tumors at the time of diagnostic implies a multimodal management either by radio-chemotherapy or chemotherapy.

\section{Declaration of conflict of interest}

Authors reveal no interest conflict with this article.

\section{References}

1. Siewert JR, Hölscher AH, Becker K, Gössner W (1987) Cardia cancer: attempt at a therapeutically relevant classification Chirurg 58: 25-32. [Crossref]

2. Mönig SP, Zirbes TK, Schröder W, Baldus SE, Lindemann DG, et al. (1999) Staging of gastric cancer: correlation of lymph node size and metastatic infiltration. AJR Am J Roentgenol 173: 365-367. [Crossref]

3. Wu AJ, Goodman KA (2013) Positron emission tomography imaging for gastroesophageal junction tumors. Semin Radiat Oncol 23: 10-15.

4. Alakus H, Batur M, Schmidt M, Drebber U, Baldus SE, et al. (2010) Variable $18 \mathrm{~F}$-fluorodeoxyglucose uptake in gastric cancer is associated with different levels of GLUT-1 expression. Nucl Med Commun 31: 532-538. [Crossref]

5. Al-Batran SE, Homann N, Pauligk C, Illerhaus G, Martens UM, et al. (2017) Effect of Neoadjuvant Chemotherapy Followed by Surgical Resection on Survival in Patient With Limited Metastatic Gastric or Gastroesophageal Junction Cancer: The AIOFLOT3 Trial. JAMA Oncol. [Crossref]

6. Moehler M, Al-Batran SE, Andus T, Anthuber M, Arends J, et al. (2011) [German S3-guideline "Diagnosis and treatment of esophagogastric cancer"]. Z Gastroenterol 49: 461-531. [Crossref]

7. Cunningham D, Allum WH, Stenning SP, Thompson JN, Van de Velde CJ, et al. (2006) Perioperative chemotherapy versus surgery alone for resectable gastroesophageal cancer. $N$ Engl J Med 355: 11-20. [Crossref]

8. Ychou M, Boige V, Pignon JP, Conroy T, Bouché O, et al. (2011) Perioperative chemotherapy compared with surgery alone for resectable gastroesophageal adenocarcinoma: An FNCLCC and FFCD multicenter phase III trial. J Clin Oncol 29: 1715-1721. [Crossref]

9. Al-Batran SE, Hofheinz RD, Pauligk C, Kopp HG, Haag GM, et al. (2016) Histopathological regression after neoadjuvant docetaxel, oxaliplatin, fluorouracil, and leucovorin versus epirubicin, cisplatin, and fluorouracil or capecitabine in patients with resectable gastric or gastrooesophageal junction adenocarcinoma (FLOT4-AIO) results from the phase 2 part of a multicenter, open-label, randomized phase $2 / 3$ trial Lancet Oncol 17: 1697-1708. [Crossref]

10. Fernandez E, Cacheux W, Frossard JL, Koessler T, Abou M, et al. (2017) Exclusive neoadjuvant chemotherapy in locally advanced resectable gastric and gastro-esophageal junction adenocarcinoma. Dig Liver Dis 49: 552-556. [Crossref]

11. van Hagen P, Hulshof MC, van Lanschot JJ, Steyerberg EW, van Berge Henegouwen MI, et al. (2012) Preoperative chemoradiotherapy for esophageal or junctional cancer. N Engl J Med 366: 2074-2084. [Crossref]

12. Anderegg MCJ, van der Sluis PC, Ruurda JP, Gisbertz SS, Hulshof MCCM, et al. (2017) Preoperative Chemoradiotherapy Versus Perioperative Chemotherapy for Patients With Resectable Esophageal or Gastroesophageal Junction Adenocarcinoma. Ann Surg Oncol. [Crossref]

13. Feith M, Stein HJ, Siewert JR (2006) Adenocarcinoma of the esophagogastric junction surgical therapy based on 1602 consecutive resected patients. Surg Oncol Clin N Am 15: 751-764.

14. Hölscher AH, Stahl M, Messmann H, Stuschke M, Meyer HJ, et al. (2016) [New S3 guideline for esophageal cancer : Important surgical aspects]. Chirurg 87: 865-872. [Crossref] 
15. Giacopuzzi S, Bencivenga M, Weindelmayer J, Verlato G, de Manzoni G (2017) Western strategy for EGJ carcinoma. Gastric Cancer 20: 60-68. [Crossref]

16. Haverkamp L, Ruurda JP, van Leeuwen MS, Siersema PD, van Hillegersberg R (2014) Systematic review of the surgical strategies of adenocarcinomas of the gastroesophageal junction. Surg Oncol 23: 222-228. [Crossref]
17. Haverkamp L, Seesing MF, Ruurda JP, Boone J, V Hillegersberg R (2017) Worldwide trends in surgical techniques in the treatment of esophageal and gastroesophageal junction cancer. Dis Esophagus 30: 1-7. [Crossref]

18. Briez N, Piessen G, Bonnetain F, Brigand C, Carrere N, et al. (2011) Open versus laparoscopically-assisted oesophagectomy for cancer: a multicenter randomized controlled phase III trial- the MIRO trial. BMC Cancer 11: 310 .

Copyright: (C2017 Mickael C. This is an open-access article distributed under the terms of the Creative Commons Attribution License, which permits unrestricted use, distribution, and reproduction in any medium, provided the original author and source are credited. 